\title{
INFLUENCE OF THE IMPACT OF ACOUSTIC CAVITATION ON THE PHYSICAL AND CHEMICAL PROPERTIES OF WATER
}

\author{
Dyussenov K. M., Sakipov K.E., Shayakhetova R.T., Nedugov I.A., \\ Aitmagambetova M. B., Yessimseit A.K.
}

\section{L.N. Gumilyov Eurasian National University, Nur-Sultan, Kazakhstan, sakamer2100@gmail.com}

\begin{abstract}
The article presents the results of an experimental study of the changing the ionic composition of water under the influence of acoustic cavitation. The effect of acoustic radiation on the physical and chemical properties of water was studied in the frequency range $20 \mathrm{~Hz}-50 \mathrm{kHz}$. It is shown that the ultrasonic range leads to an increase in the concentration in the area of metal traces and affects the change in the $p H$ of water. The mechanism of action of cavitation leads to a change in the structural characteristics of water. It is shown that one of the manifested effects of ultrasonic cavitation can be used for various applications.
\end{abstract}

Keywords: ultrasound, acoustic emission, cavitation, mass spectrometric analysis.

\section{Introduction}

The data of the materials of the International Committee on Water Resources at the UN (United Nations), WHO (World Health Organization) and other generally recognized and specialized international expert organizations that fresh and especially drinking water will become a strategic resource by 2025 are well known. Water quality issues for drinking, agricultural irrigation and irrigation are becoming more acute. The relevance and relevance of practical applications in the field of water treatment and treatment is beyond doubt. The boom in demand for nanotechnology, new technologies in various ways of structuring water, other liquids and solutions is growing exponentially. In work [1], a wide range of applications of acoustic (ultrasonic) and hydrodynamic cavitation in various fields of science and high technologies was thoroughly investigated. Changes in the properties of water under the influence of hydrodynamic cavitation were also noted in [2], where studies were carried out on the basis of numerical modeling. The range of technical applications of hydrodynamic and ultrasonic cavitation in the world is rapidly expanding when they are directly used in medicine, naval affairs, pharmaceuticals, chemical technologies, cosmetics and cosmetology, etc. pressure of hydraulic microjets up to $40 \mathrm{MPa}$ causes ionization of water and aqueous solutions and is accompanied by many poorly studied processes.

Studies of the influence of hydrodynamic cavitation on the change in the physicochemical properties of aqueous solutions are devoted to works [3-5], and works [6,7] are shown to purify water both from bacteria and other contaminants, and to disinfect water. Ultrasonic cavitation can also lead to changes in cellular structures, as shown in [8], and can be used in cancer therapy. The phenomenon of hydrodynamic cavitation was also used to purify water from pharmaceutical contaminants [9]. It is known that it influences the growth and development of cell structures and the transfer of various substances into cells under the influence of acoustic frequencies and cavitation of a different spectrum [10, 11]. For example, in [12, 13], the influence of ultrasonic acoustic emission, accompanied by cavitation, on various structural characteristics of water, including some aspects of physical chemistry and microbiological composition, was studied.

It is obvious that the use of hydrodynamic and ultrasonic cavitation is an example of nanotechnology, and many aspects of this effect are poorly understood. The questions were studied in detail and the results of the influence of the infrasonic spectrum of oscillations on the growth of some types of cereals were used. The issues of structuring water under the influence of cavitation continue to be studied and are of interest in various fields, including crop production and agricultural technology.

\section{Experimental part. Materials and method}

For this, two experimental installations were created for the generation of infrasound and ultrasound with the subsequent transfer of the pulse to piezoelectric transducers (emitters). The generator unit consists of a pulse generator and a frequency amplification unit of a special shape, a power supply unit and a control 
panel. Direct action on water is carried out in a radiation installation through piezoelectric transducers using a device for generating infrasound and ultrasound (Fig.1), [14]. The frequency spectrum of radiation before and after experiments on the effect of irrigation with acoustic vibrations was recorded using a VALLEMAN PC SGU250 broadband oscilloscope and the adjustment range was from 20-50 Hz on the first block to 20-50 $\mathrm{kHz}$ per second.

The water was subjected to ultrasonic action using the emitters shown schematically in Fig. 2. Ultrasonic emitters are made in the form of flat piezoelectric emitters for generating ultrasonic pulses located on the inner surface equidistantly relative to the flow path of the cavitation generator on two opposite sides and connected in parallel with the formation of a cavitation field directed perpendicular to the fluid flow.

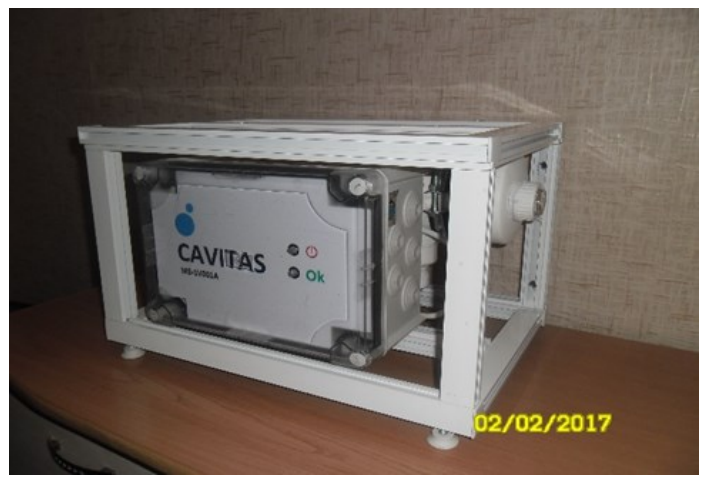

Fig.1. The device for generating infrasound and ultrasound.

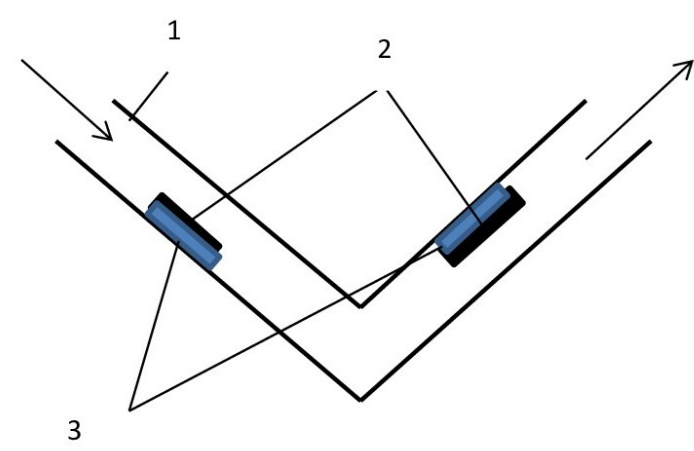

Fig.2. Emitter layout.

Ultrasonic piezoelectric emitters are made of barium titanite, which allows generating a high-frequency spectrum of ultrasonic radiation. The ultrasonic emitters are rigidly fixed to the nozzle, for example, using a composite adhesive and are completely sealed against the corrosive effects of a liquid medium. Water flows through the inlet nozzle 1 and under the influence of ultrasonic transmitters 2 rigidly fixed to the inner surface of the dielectric wall nozzle using an adhesive or adhesive material such as composite adhesive 3 (Fig. 2). The coolant is exposed to ultrasonic action due to pulses supplied from ultrasonic transducers 2, which are turned on perpendicular to the direction of fluid flow. The frequency spectrum of ultrasonic transducers varies from $20 \mathrm{KHz}$ to $50 \mathrm{MHz}$, and the "traveling wave" is generated by an adjustable microprocessor and is automatically correlated with the flow rate of the coolant. Since the frequency of the radiation spectrum is adjustable, this makes it possible to control the processes of the intensity of the generation of cavitation cavities, depending on a number of physical factors, including both the speed and flow rate of the coolant flow, and the diameter of the inlet pipe. Along the length of the zone of action of ultrasonic emitters 2, cavitation cavities begin to form in the entire volume of the inlet pipe of the moving coolant, which, after passing the inlet pipe, begin to "collapse" (collapse), while releasing the amount of heat adequate to the breaking energy of intermolecular bonds. In addition, the effect of "cold boiling" or the formation of cavitation cavities with their subsequent collapse (collapse) leads to ionization of the coolant throughout the volume of the supply pipe and a controlled change in its physicochemical properties.

In [15] on physical and technical acoustics, ultrasonic cavitation usually means the formation of discontinuities in the continuity of a liquid medium under the action of tensile stresses in the rarefaction phase, the emergence of unstable vapor-gas cavities and the subsequent collapse of these cavities in the compression phase.

\section{Results and Discussion}

The frequency spectrum of the radiation in the range $20-50 \mathrm{~Hz}$ virtually did not affect the $\mathrm{pH}$ of irrigation water. The most characteristic effects on the structure of irrigation water at $20 \mathrm{~Hz}$ manifested in increasing cadmium concentration by almost $92 \%$ zinc and almost 7 times. As seen from the integrating spectrograms where abscissa mg dm-3 drawn on generalized results of analyzes of samples (Fig. 3, 4) with a sharp increase in the concentration of cadmium Cd (about 4 times), and tin Sn (by 11 times) the remaining group trace metals have remained virtually unchanged. 


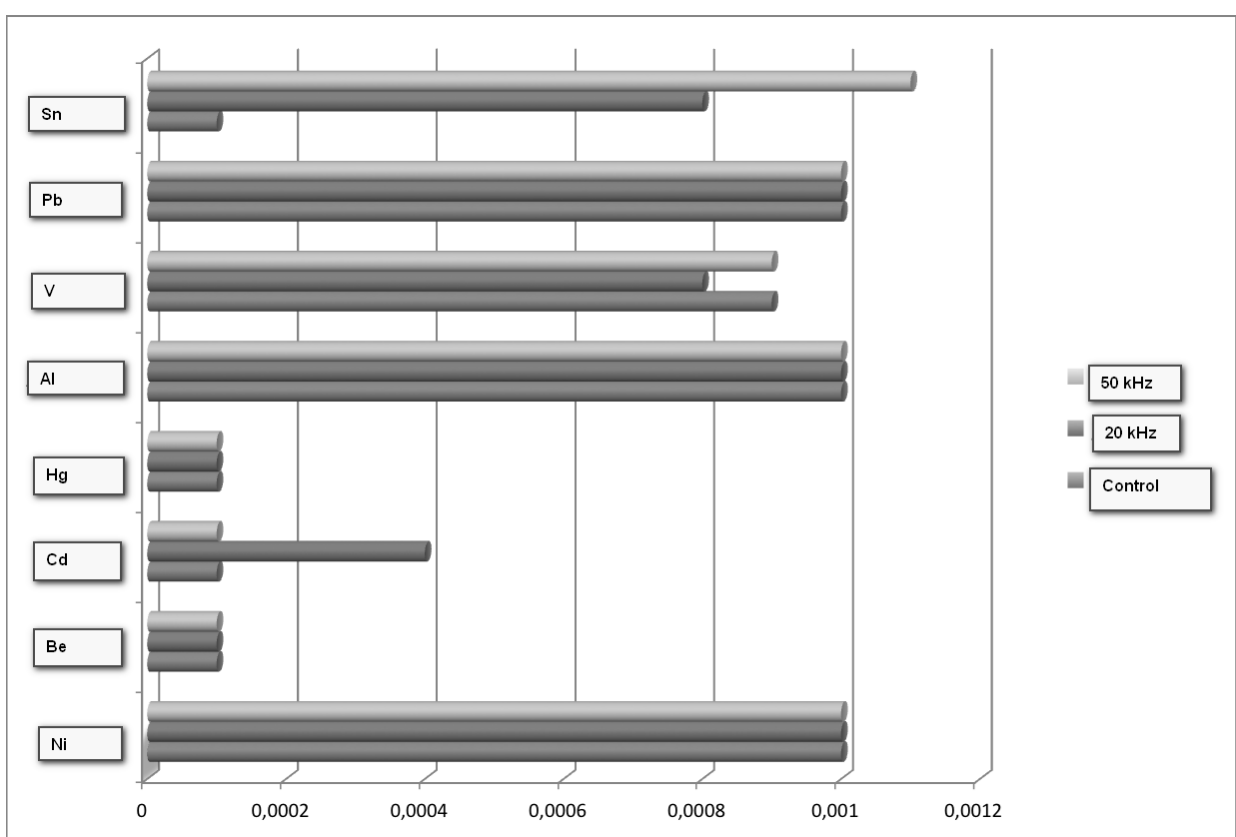

Fig. 3. The increasing of $\mathrm{Sn}$ and $\mathrm{Cd}$ concentration in water after ultrasound influence

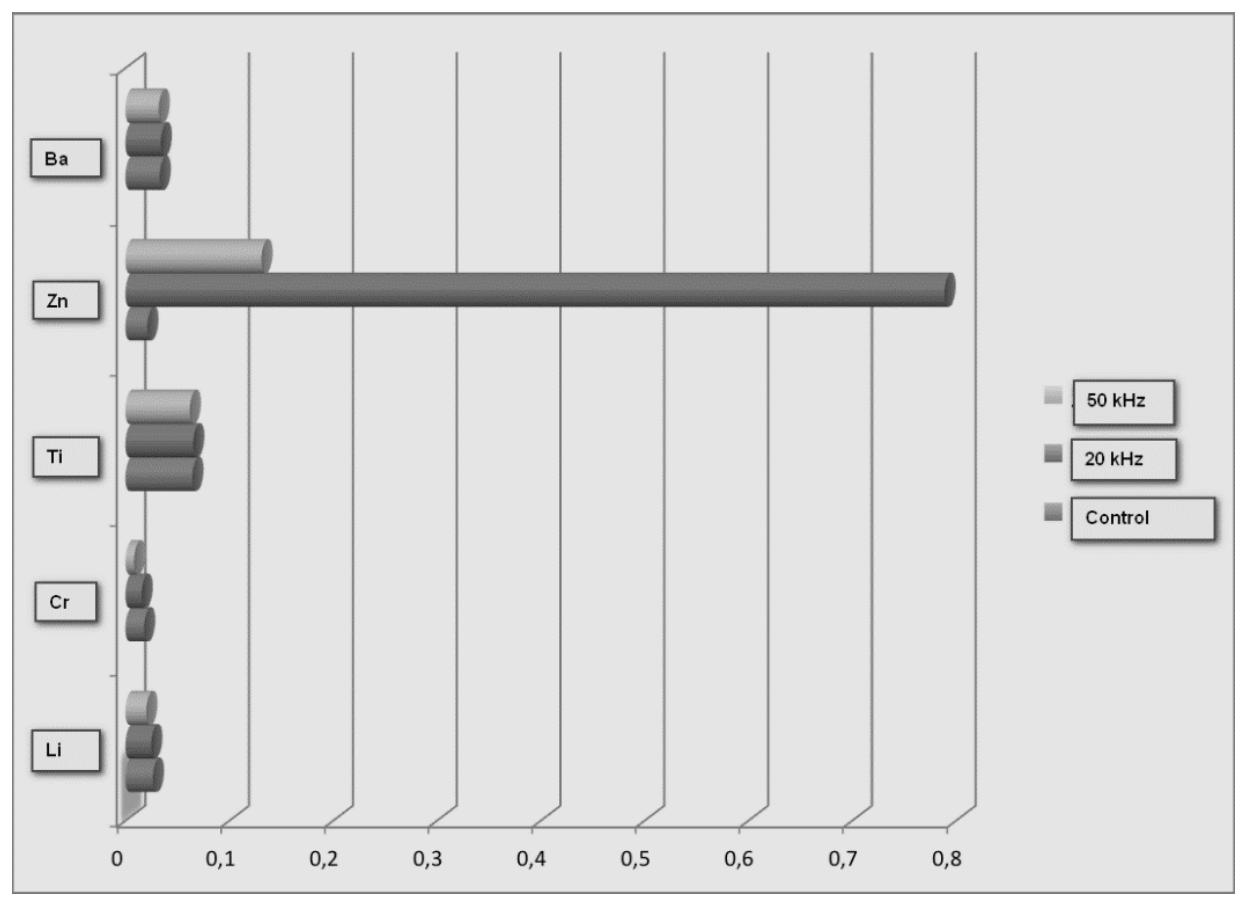

Fig.4. The increasing of $\mathrm{Zn}$ concentration in water after ultrasound influence.

At the same time, the content is within the MPC as the EU countries and the United States, Russia and the MAC recommended by WHO. For example, MPC WHO compared with the obtained data are shown in Table. 1. The highest efficiency of irrigation water gave exposed to ultrasound in a range close to $20 \mathrm{kHz}$, the second pilot unit.

Table 1. The comparative characteristics of the content of trace minerals

\begin{tabular}{|c|c|c|}
\hline $\begin{array}{c}\text { MAC (WHO), } \\
\mathrm{mg} / \mathrm{dm}^{3}\end{array}$ & $\begin{array}{c}\text { After influence } 20 \mathrm{kHz}, \\
\mathrm{mg} / \mathrm{dm}^{3}\end{array}$ & $\begin{array}{c}\text { After influence } 50 \mathrm{kHz}, \\
\mathrm{mg} / \mathrm{dm}^{3}\end{array}$ \\
\hline $\mathrm{Cu} 0.20$ & 0.14 & 0.136 \\
\hline $\mathrm{Zn} 0.30$ & 0.231 & 0.148 \\
\hline $\mathrm{Cd} 0.003$ & 0.00039 & 0.00011 \\
\hline
\end{tabular}


Results of averaged spectrograms in $\mathrm{mg} / \mathrm{dm}^{3}$ (Fig. $5-6$ ) show that a pronounced positive effect on the growth of tomato at a frequency range of $20 \mathrm{kHz}$ the radiation had growth of concentration iron of $22 \%$, copper $\mathrm{Cu}$ in 1.6 times and manganese $\mathrm{Mn}$ by 8 times.

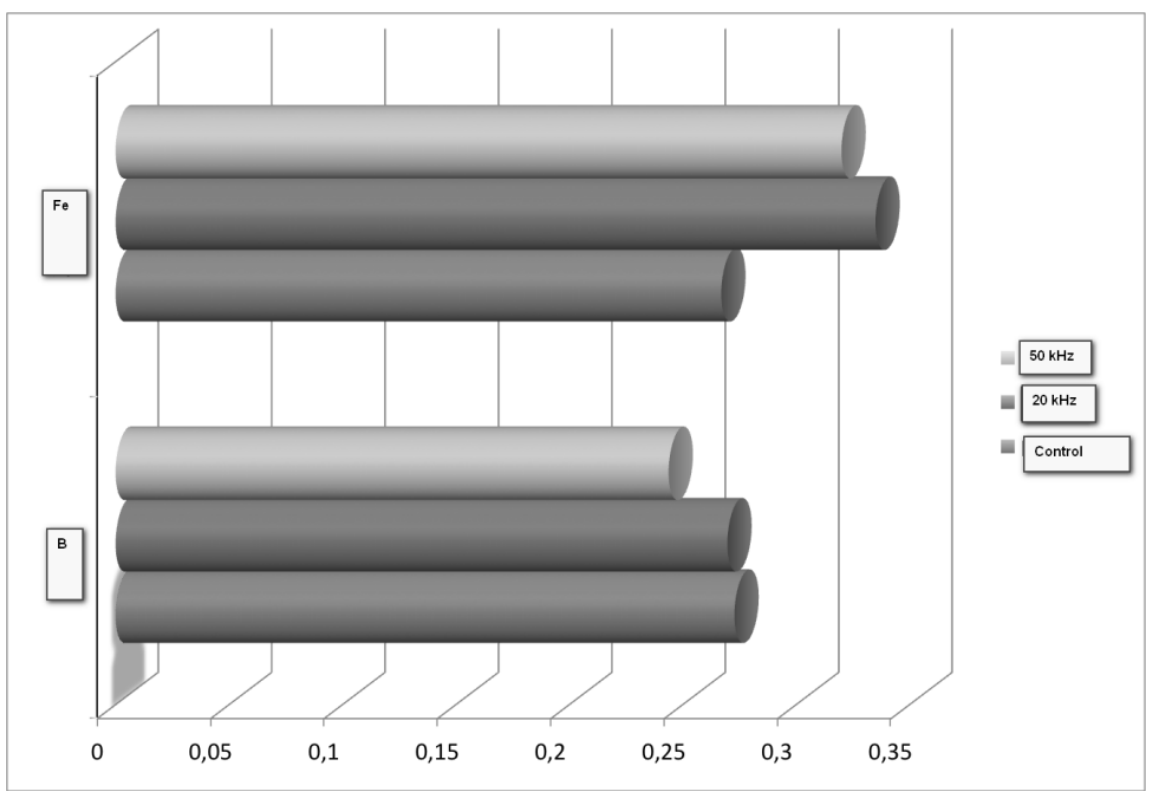

Fig.5. The increasing of Fe concentration in water after ultrasound influence

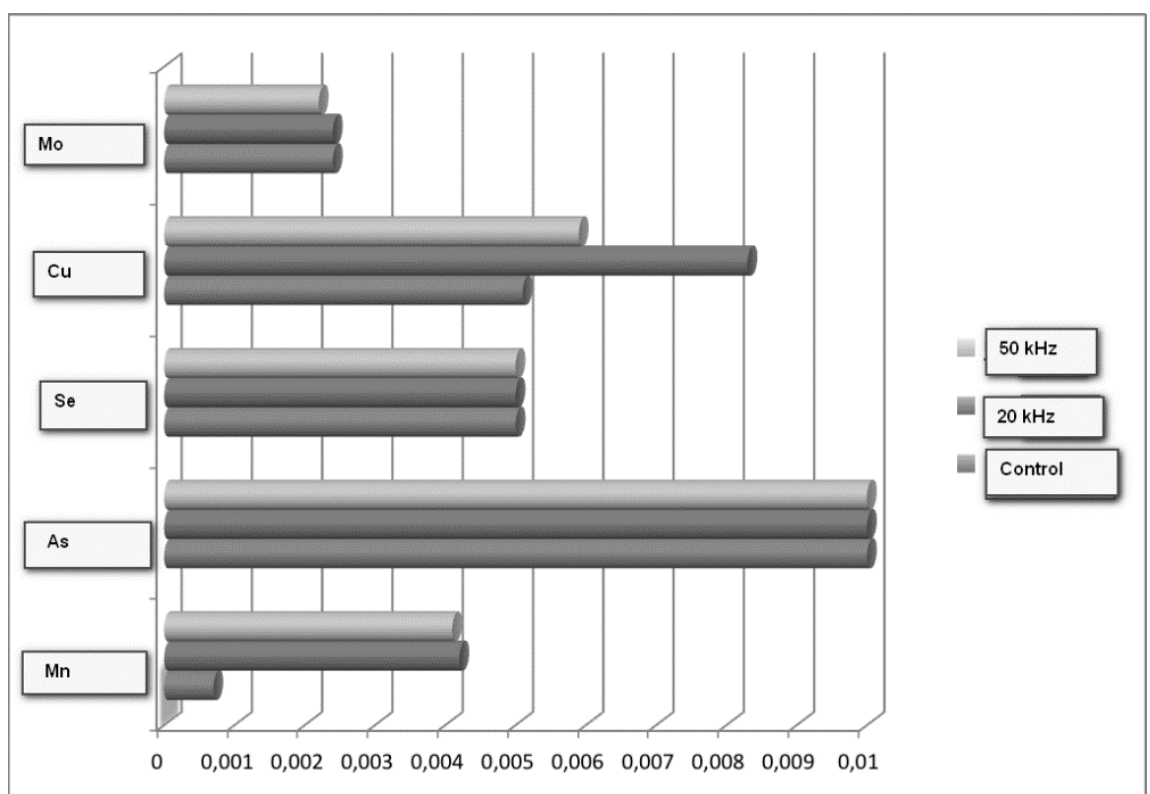

Fig.6. The increasing of $\mathrm{Cu}$ and $\mathrm{Mn}$ concentration in water after ultrasound influence

Thus, minor, an average of $1.14-2.01 \%$ grew acidity $(\mathrm{pH})$ of the treated water for irrigation at $20 \mathrm{kHz}$ and at a frequency of $50 \mathrm{kHz} \mathrm{pH}$ values increased to $3.28 \%$. Analysis of the spectrograms and measurement of irrigation water $\mathrm{pH}$ after ultrasonic treatment led to the conclusion that the water gets new properties related to its partial ionization leading to changes in its molecular structure.

A number of works are known, among them [15], where various scientific explanations of the phenomenon of hydrodynamic and ultrasonic cavitation are given, accompanied by the processes of changing the mechanism of microalgae development. It is the cavitation mechanism that causes new effects of molecular changes in the structural characteristics of algal cells was shown in these studies.

It is quite obvious that ultrasonic and hydrodynamic cavitation has a rather complex mechanism of affecting water and aqueous solutions and is manifested in many physical and chemical aspects. Mass spectrometric analysis of irrigation water allowed to illustrate that partial ionization of irrigation water 
occurs with activation of metal ions dissolved in it. In all probability, the activated metal ions, the concentration of some of which increased several times in the form that ultrasonic cavitation caused, greatly improve and intensify plant growth and appear as one of the factors contributing to this.

\section{Conclusions}

For the first time, data were obtained on the change in the physicochemical properties of water under the influence of ultrasonic cavitation in the radiation range from 20 to $50 \mathrm{kHz}$. The accuracy and reproducibility of all experimental data in the specified frequency range fully meet the standard requirements. The measuring equipment used in the work meets international quality and accuracy standards. Changes in the physicochemical properties of water affect the complex mechanism of the physical effects of cavitation, which were analyzed on the basis of data from other authors. The effects of sono luminescence, the collapse of cavitation microbubbles lead to additional ionization and activation of water. The data presented on the change in the structure of water after exposure allow us to conclude that cavitation has a significant effect on the molecular composition of water. The analysis of the effect of ultrasonic cavitation on water brings new knowledge and data in a deeper study of the phenomenon of cavitation. The data on the increase in the concentration of ions of dissolved metals obtained using mass spectrometry and changes in the $\mathrm{pH}$ of water make it possible to expand the range of scientific data on the practical use of this effect in various agrotechnical and engineering applications.

\section{REFERENCES}

1 Li B., Gu Yo., Chen M. Cavitation inception of water with solid nanoparticles. A molecular dynamics study. Ultrasonics -Sonochemistry. 2019, Vol. 51, pp. 120-128.

2 Yusvika M., et al. Cavitation Prediction of Ship Propeller Based on Temperature and Fluid Properties of Water. Journal of Marine Science and Engineering, 2020, Vol. 8, Iss. 6, pp. 2-21.

3 Loraine G., Chahine G., Hsiao C.T., Choi J.K., Aley P. Disinfection of gram-negative and gram-positive bacteria using DynaJets ${ }^{\circledR}$ hydrodynamic cavitating jets. Ultrasonics Sonochemistry, 2012, Vol. 19(3), pp. 710 - 715.

4 Badve M., et al. Hydrodynamic cavitation as a novel approach for wastewater treatment in wood finishing industry. Separation and Purification Technology. 2013, Vol.106, pp. $15-21$.

5 Vasenin I.M., Narimanov R.K., Perchatkina E.V., Shrager L.A. Investigation of two phase flow motion with small-size gas bubbles. Eurasian Physical Technical Journal, 2019, Vol.16, No.2 (32), pp. 48 - 54.

6 Al-Mahrouki A.A., Karshafian R., Giles A., Czarnota G.J. 2012. Bioeffects of ultrasound-stimulated microbubbles on endothelial cells: Gene expression changes associated with radiation enhancement in vitro. Ultrasound Med Biol. 2012, Vol.38, pp. 1958 - 1969.

7 Kuwabara Mamoru, Yo Ken, Kubo Takashi. Sono-processing of materials based on an acoustic cavitation phenomenon. Journal of Current Advances in Materials and Processes. 2005, Vol.18, No. 4, pp. 962 - 969.

8 Zupanc M., Tina Kosjek T., Petkovšek M., et al. Shear-induced hydrodynamic cavitation as a tool for pharmaceutical micropollutants removal from urban wastewater. Ultrasonics Sonochemistry, 2014, Vol. 21, Issue 3, pp. $1213-1221$.

9 Chuang Y.H., Cheng P.W., Chen S.C., et al. Effects of ultrasound-induced inertial cavitation on enzymatic thrombolysis. Ultrason Imaging. Apr. National Taiwan University, Taipei, Taiwan. 2010, Vol. 32(2), pp. 81-90.

10 Riesz P., Berdahl D., Christman C.L. 1985. Free radical generation by ultrasound in aqueous and nonaqueous solutions, Environ Health Perspective. 1985, Vol. 64, pp. 233 - 252.

11 Hernández-García D., Castro-Obregón S., Gómez-López S., Valencia C., Covarrubias L. Cell death activation during cavitation of embryoid bodies is mediated by hydrogen peroxide, Experimental Cell Research, 2008, Vol. 314, Issue 10, pp. 2090 - 2099.

12 Villanueva M.V., Luna M.C., Gil M.I., Allende A. Ultrasound treatments improve the microbiological quality of water reservoirs used for the irrigation of fresh produce. Food research international. 2015, Vol. 75, pp. 140 $-147$.

13 Pan Li, Yuan Song, Shuili Yu, Hee-Deung Park. 2015. The effect of hydrodynamic cavitation on Microcystis aeruginosa. Physical and chemical factors. Chemosphere, 2015, Vol. 136, pp. $245-251$.

14 Dyussenov K., Nedugov I. Cavitation energy converter: Patent Provisional Application, USA, Number 61745772. Publ. 25.12.12, $21 \mathrm{p}$.

15 Nyborg, W.L. Physical Mechanisms for Biological effects of Ultrasound. DHEW 78-8062. Washington, D.C., U.S. Government Printing Office, 1977, pp. 59-64. 